\title{
A questão ambiental e a saúde
}

Fernando Ferreira CARNEIRO ${ }^{1}$

\section{INTRODUÇÃO}

O reconhecimento da importância das questões sociais, ambientais e econômicas como determinantes para a saúde está relacionado à evolução dos paradigmas sobre a saúde desde os tempos do tratado “Dos ares, águas e lugares" de Hipócrates, passando pelos estudos sobre a precariedade da situação de vida da classe trabalhadora no período da Revolução Industrial, até a complexa trama de contextos e riscos associados ao modelo de desenvolvimento globalizado ${ }^{1}$.

A Reforma Sanitária brasileira pode ser considerada um processo de transformação da norma legal e do aparelho institucional em um contexto de democratização que correspondeu a um efetivo deslocamento do poder político em direção às camadas populares em prol da proteção à saúde dos cidadãos, cuja expressão material concretiza-se na busca do direito universal à saúde e na criação de um sistema único de saúde sob a égide do Estado².

Apesar dos avanços reconhecidos no modelo brasileiro - universalização, integralidade, participação social, institucionalizados e presentes no seu arcabouço jurídico, o SUS realdifere do SUS idealizado pela Reforma Sanitária. Esta desarmonia existente entre o SUS desejado e o SUS da vida real é resultado de mudanças no contexto político, social e econômico do Brasil e função da globalização.

\section{UMA AGENDA QUE VEIO PARA FICAR?}

A questão ambiental e suas relações com a saúde humana estão sistematicamente na agenda nacional e internacional, tanto no que se refere às políticas públicas quanto aos movimentos sociais e à academia.

Considerando as dimensões e os desafios inerentes aos problemas político-econômicos, ambientais e sanitários que emergem neste campo, é fundamental um entendimento que possibilite a elaboração de alternativas viáveis para a resolução ou o controle de seus efeitos ${ }^{3}$.

Apesar dos grandes avanços obtidos com a consolidação do SUS, como a descentralização da gestão, criação dos Fundos de Saúde, o fortalecimento da rede pública, o aumento da cobertura de serviços de nível básico, o funcionamento dos conselhos de saúde, o desenvolvimento do sistema

1 Doutor em Ciência Animal - área de concentração de Medicina Veterinária Preventiva e Epidemiologia pela Universidade Federal de Minas Gerais. Coordenador do Observatório da Política Nacional de Saúde Integral das Populações do Campo e da Floresta - Teia de ecologia de saberes e práticas. Contato: fernandocarneiro.brasilia@gmail. com 
nacional de vigilância da saúde, a política de medicamentos genéricos e a formação de banco de preços etc., ainda nos deparamos com importantes dilemas e desafios.

As questões hoje colocadas e relacionadas ao futuro do Brasil, a um projeto de país e de nação na qual a saúde da coletividade esteja efetivamente assegurada, perpassam os ambientes para além das unidades de saúde e dos hospitais. A discussão do modelo de desenvolvimento econômico e social do país é um dos desafios que precisam ser discutidos considerando o olhar do setor saúde.

Podemos ilustrar este desafio com o envolvimento do MS nas discussões em torno da construção da BR 174 ou da revitalização da Bacia do São Francisco, por exemplo. Enquanto uma será o escoadouro de toda soja do norte e centro-oeste do país, o outro projeto envolve mais de 8 milhões de pessoas que vivem na região mais pobre e desigual do país.

Com a inserção marginal e periférica do MS nesta discussão, sem um peso de um projeto de sustentabilidade para aquela população, tem sido desperdiçado o espaço para politizar a questão e retomar os ideais alcançados pelo Movimento da Reforma Sanitária e que deve ser aprimorado.

Estudos do Ipea alertam para a mudança do perfil da pauta de exportações brasileiras. Entre 2007 e 2010, commodities avançaram de $41 \%$ para 51\% no total de produtos vendidos pelo Brasil ao exterior.

As exportações brasileiras na última década vêm se especializando em bens agrícolas in natura, alimentos diversos, minérios e metais, e combustíveis. Por sua vez, o percentual da exportação de bens manufaturados decresceu continuamente, havendo passado de 58,4\%, em 2000, a 37,1\%, em 2010. Ademais, a exportação dos manufaturados de alta tecnologia passou, no período, de 18,7 para $11,2 \%$, do total dos manufaturados exportados, ou seja, nossa economia esta se reprimarizando ${ }^{4}$.

Segundo dados do Ministério do Desenvolvimento, Indústria e Comércio Exterior (MDIC), a partir de 2009, o Brasil passou a ter um volume maior de exportações para a China do que para os Estados Unidos.

Em 2011, 85\% do valor das exportações brasileiras para a China eram compostas de bens primários. Portanto, pelo lado das exportações, a economia externa brasileira depende cada vez mais de recursos naturais, embora a produção desses bens seja cada vez mais sofisticada, graças ao emprego intensivo de tecnologias e de processos de trabalho organizados em moldes industriais.

Esse modelo levou o Brasil, por exemplo, a ser o maior consumidor de agrotóxicos do planeta por seis anos consecutivos, o que determina uma série de impactos a saúde das populações mais vulneráveis do campo, como também às populações que consomem esses alimentos nas cidades ${ }^{4}$.

À partir desse contexto deve-se olhar para o perfil de saúde da população brasileira. Historicamente construído, o quadro de saúde atual está dominado por três grupos de agravos, // Tempus, actas de saúde colet, Brasília, 8(1), 79-83, mar, 2014.

ISSN 1982-8829 
todos eles condicionados por diferentes contextos sócio-ambientais. O primeiro deles revela, predominantemente, doenças cardiovasculares e neoplásicas (respectivamente primeira e terceira causas de óbito), cuja tendência crescente nos últimos dez anos acompanha o envelhecimento da população.

Esta situação se torna possível na medida em que estas expressões mórbidas são consideradas como efeito de condições genéticas, de vida e trabalho vivenciadas por estas populações, principalmente aquelas expostas a determinados poluentes ambientais. O segundo grupo é conformado pelas Doenças Infectoparasitárias, nitidamente determinadas também pelas condições sócio-ambientais. As chamadas causas externas compõem o terceiro cenário que englobam os acidentes e violências. Ambos constituem-se como acontecimentos sócio-ambientais produtores de traumas, lesões e doenças ${ }^{5}$.

Analisando este perfil, podemos sugerir que a construção do SUS frente a este diagnóstico passa pela atuação sobre os determinantes e condicionantes deste quadro. A racionalidade médica hegemônica no SUS dificilmente encontrará soluções coerentes com os anseios de qualidade de vida da população brasileira.

Existe um campo enorme de atuação e uma agenda que foi perdida, mas deve ser recuperada. Os esforços para romper barreiras institucionais na discussão de projetos que ultrapassam estas fronteiras têm sido um dos objetos de trabalho do campo da Vigilância em Saúde Ambiental, da política de saúde dos povos do campo e da floresta, envolvendo grupos que historicamente foram desconsiderados como atores estratégicos no processo de desenvolvimento do país. Outro espaço de articulação chave é junto ao Ministério das Cidades. As questões relacionadas ao saneamento e a habitação ainda significam uma enorme dívida social do Estado brasileiro com sua população e isto tem um impacto determinante na saúde dos brasileiros. O Ministério da Saúde precisa encarar como uma importante prioridade sua participação na implementação de um plano de saneamento ambiental para o país.

\section{UM NOVO OLHAR...}

A interface entre saúde e ambiente, sob o marco da sustentabilidade, compreende a instituição de uma política que expresse a multiplicidade de forças interativas geradas (diversidade de "olhares" e "interesses") em torno da promoção da vida do planeta e da saúde humana.

No âmbito das políticas públicas, no atual arranjo das atribuições no governo federal, este campo relaciona diretamente quatro ministérios: saúde, meio ambiente, trabalho e emprego e cidades.

A construção de uma referência conceitual da interface entre saúde e ambiente, com vistas à implementação de uma política de saúde para este fim, recoloca na ordem do dia a necessidade de "aprimoramento" do atual modelo de atenção do SUS, onde a agenda da promoção da saúde seja 
compreendida numa dimensão em que a construção da saúde é realizada fundamentalmente, embora não exclusivamente, fora da prática das unidades de saúde, ocorrendo nos espaços do cotidiano da vida humana, nos ambientes dos processos produtivos e na dinâmica da vida das cidades e do campo, buscando compreender o ambiente como um território vivo, dinâmico, reflexo de processos políticos, históricos, econômicos, sociais e culturais, onde se materializa a vida humana e a sua relação com o universo.

Neste sentido, o SUS tem o desafio de criar frestas no percurso - sociológico e geográfico - que existe entre a vida real das pessoas e a procura aos serviços de saúde. É necessário e urgente que seja implementada uma prática que seja voltada para os determinantes e condicionantes da saúde, a partir da qual se poderia construir um novo ciclo do SUS. É nesse percurso onde devemos nos ater.

Os desafios que temos que enfrentar estendem-se a toda organização social, desde a produção, distribuição e consumo de bens e serviços até as formas de organização do Estado e seus aparelhos em suas relações com a sociedade, inclusive a sua cultura ${ }^{6}$.

Para o desenvolvimento atual há necessidade de fazer parcerias, de inovação, de criar ambientes favoráveis à sinergia e aproveitar os resultados e potencialidades da simbiose. Estes são conceitos primordiais da mudança.

Dessa maneira, a velha idéiade crescimento se transforma em uma nova concepção de desenvolvimento e sustentabilidade.

\section{REFERÊNCIAS BIBLIOGRÁFICAS}

1 - CARNEIRO, F F ;NETTO, GF ; CORVALAN, C ; FREITAS, C M ; SALES, L B F. Saúde ambiental e desigualdades: construindo indicadores para o desenvolvimento sustentável. Ciência e Saúde Coletiva (Impresso), v. 17, p. 1419-1425, 2012.

2 - Anamaria Testa Tambellini, apresentação oral durante a Oficina de Planejamento da CGVAM/ SVS/ MS, Brasília 19 de setembro de 2003.

3 - TAMBELLINI, A \& MIRANDA, A. Saúde e Ambiente: IN Políticas e Sistemas de Saúde no Brasil. CEBES e ABRASCO, Rio de Janeiro, 2012.

4 - CARNEIRO, F. F.; PASSOS, R. ; SEGATO, R. ; PEREIRA, M. F. Perspectivas emancipatórias sobre a saúde e o Bem Viver face às limitações do processo de desenvolvimento brasileiro. Saúde em Debate, v. 36, p. 106/115, 2012.

5 - SANTOS, Thereza Christina Carvalho; CÂMARA, João Batista Drumond (Org.). GEO BRASIL - Perspectivas do Meio Ambiente no Brasil. Brasília: Edições IBAMA, 2002. 
6 - PAIM, J.S. Saúde-política e reforma sanitária. Salvador. ISC- Instituto de Saúde Coletiva, 2002. 447 p.

Artigo apresentado em 10/01/14 Artigo aprovado em 21/03/14 Artigo publicado no sistema: 28/03/14 